\title{
BEHAVIOR OF BEAM-TO-COLUMN CONNECTIONS WITH ANGLES. PART 1-EXPERIMENTAL INVESTIGATIONS
}

\author{
M. Ghindea a, A. Cătărig a,*, R. Ballok a \\ ${ }^{a}$ Technical University of Cluj-Napoca, Faculty of Civil Engineering, 15 C. Daicoviciu Str., 400020, Cluj-Napoca, Romania
}

Received: 10.09.2015 / Accepted: 10.10.2015 / Revised: 30.10.2015 / Available online: 15.12.2015

DOI: $10.1515 /$ jaes-2015-0017

KEY WORDS: experimental investigation, beam-to-column joint, semi-rigid connection, steel, bolted connection, angle cleat

\begin{abstract}
:
In this paper, four specimens of steel beam to column joints with different configuration of bolted angle connections are experimentally tested. The specimens are double sided beam to column connections and are tested under bending loading conditions in order to investigate elastic and inelastic connection behaviour. The semi-rigid beam-to-column connections were subjected to monotonous static loading. The bolted beam-to-column connections are composed from top and seat angle connections with and without web angles as well as with stiffened top and seat angle cleats. The intent of the experimental investigations is to highlight the ability of the connections to maintain strength and to provide rotational capacity. The experimental results are evaluated with the measured force displacement data, from which the characteristic moment-rotation curves were established. The experimental results indicate the primary failure modes include member deformation. The moment-rotation relationship of the tested joints exhibits a significant inelastic nonlinear response. The paper concludes with the comparison of the tested joints in terms of strength and stiffness, highlighting the advantages and weaknesses of the studied joint typologies.
\end{abstract}

\section{INTRODUCTION}

The connections of steel structures are one of the determining factors of economy in structural steel work. Moreover the manual evaluation of bolted connection is a difficult task. The selection of connections is often based upon simplicity, duplication and ease of erection, which can be done with relatively unskilled workers and with basic tools. From this point of view the designer have to avoid complicated joint configurations with costly fabrication and laborious design.

In the structural analysis practice of multistorey steel framed structure, the connections of beam-tocolumn are considered to be simplified, rigid or

* Corresponding author. e-mail: alex.catarig@mecon.utcluj.ro 
pinned: rigid implies complete rotational continuity and pinned implies no moment transfer (Csebfalvi, 2007). Besides these classical connections there is another category called semi-rigid connections (Xiaoguang Lin, 2004). Analysis of frame structure with semi-rigid joints requires the performance of joints in terms of moment-rotation behavior (Pirmoz, 2009; Mahmoud, 2011). Taking into account the behavior of semi-rigid connections results closer to the reality are obtained (White, 2003; Ivanyi, 2000). The main advantage of a frame design using semi-rigid joint behaviour is that beam moments are reduced leading to lighter beam. Therefore, assuming appropriate semi-rigid connections, the moments value can became more balanced, without high extreme values.

Experimental researches aimed to find out momentrotation curves of connections as this is the main way to characterize connections (Alexa, 2005; Bjorhovde, 1996). Attention is focussed on moment-rotation characteristics as this is the most important influence on the response of either individual members or entire frames. Although the literature provides a high volume of studies on semi-rigid behavior of joints, they are not used as such in the usual designing practice (Altman, 1982; Aziznamini, 1987; White, 1996). The considerable amount of research conducted over the last two decades has not produced many design procedures that would allow the applications of connections in design process. Most of the structural calculation programs allow defining a flexible connection at the end of the bars in terms of rotational springs, but these moment-rotation curves are available for a relatively small number of joints types and their parameters.

A well known typology of semi-rigid beam-tocolumn connection is bolted angles connection. The advantages of manufacturing with low cost and complexity made them to be studied in different fundamental modes (experimental, numerical and analytical) (Reynosa, 2015; Loureiro, 2011; Azizinimani, 1982; Leon, 2000). There are several advantages provided by bolted joints like reduced cost and reduced complexity of execution.
Compared to welded joints these connections are more ductile, have a relatively high capacity to dissipate energy and are made relatively easy.

The experimental program performed by the author includes laboratory tests on four nodes specimens with double sided beam-to-column connections. Those four specimens have different configurations, depending on the angles arrangement within the joint. The study of these joints represents an extension of the tests performed at the Technical University La Corunia (Reynosa, 2014; Reynosa, 2015). Thus, in order to perform real comparisons between reference tests and the tests carried out by the author, the first tested specimen is identical in terms of configuration, with the TSW-10 joint (top-and-seat with web angle connection, with $10 \mathrm{~mm}$ angles thickness), experimentally tested by Reynosa J.M. (Reynosa, 2014).

\section{GEOMETRY OF THE SPECIMENS AND OF THE TEST SETUP}

The tested specimens are joints with double-sided beam-to-column connections at 1:1 scale. The configuration thereof is shown in table 1 .

\begin{tabular}{|c|c|c|}
\hline Specimen & $\begin{array}{c}\text { Top and seat angle } \\
\text { cleat }\end{array}$ & $\begin{array}{l}\text { Web angle } \\
\text { cleat }\end{array}$ \\
\hline TSW-10 & L120x90x10 & L100x10 \\
\hline TS-10 & L120x90x10 & - \\
\hline TSS-10 & L120x90x10 & - \\
\hline TSWS-10 & L120x90x10 & L100x10 \\
\hline
\end{tabular}

Table 1. Joint configuration proposed for testing

The specimens proposed for testing are manufactured as such:

- TSW-10, bolted top-and-seat with double-web angle connection (left-right)

- TS-10, top-and-seat angles cleat connection,

- TSS-10, stiffened top-and-seat angle cleats (with triangular angle cleat fixed with tee welding), 
- TSWS-10, stiffened top-and-seat with double-web angle (left-right) (with triangular angle cleat fixed with tee welding).

The bolts used to fix the angle cleats are group 10.9, and were pre-tensioned using a torque wrench. The tolerance of the bolt hole is $1 \mathrm{~mm}$.

The proposed specimens for testing are considered as being supported at the end of the beams and on the column head. The symmetrical configuration of the specimens has the advantage that rotations produced in joints are exclusively relative rotations, the column having a fixed position during the test.

Next to the supports have been arranged stiffeners welded on the beam web in order to provide an increased load bearing capacity to concentrated shears.

Figure 1 shows the test setup for the specimens and elements belonging to the experimental bench.

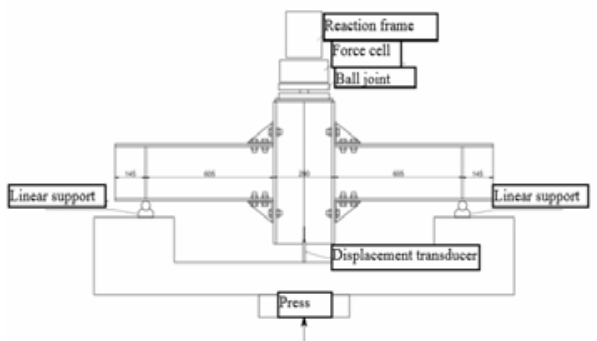

Figure 1. Test setup

Parameters monitored during experimental tests are needed to generate characteristic moment-rotation curves. Thus, through a force cell located between specimen and reaction frame, the total applied loading was monitored.

Vertical movements of the beam ends were recorded using two inductive WA type displacement transducers from HBM technology (HBM Test and Measurement: WA Inductive Displacement Transducer).
The displacement transducers and the force cells were connected to an acquisition station (HBM Test and Measurement; Spider 8), the experimental data being recorded and stored on the computer using the dedicated CatmanEasy software (HBM Test and Measurement, Catman Easy software). The above presented instruments used to measure the desired parameters during testing are illustrated in figure 2 .

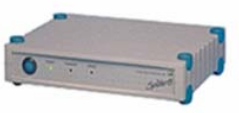

a)

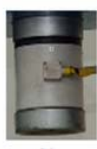

b) c)

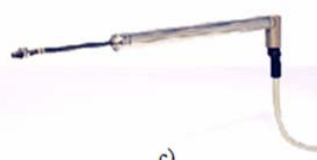

Figure 2. Monitoring tools (a. Spider 8 acquisition system, b. HBM load cell, c. WA-transducer)

The loading process for connection performances assessment is monotonous static, having a loading speed of approx. $3 \mathrm{~mm}$ per minute.

\section{IMPLEMENTATION AND RESULTS}

\subsection{TSW-10 test}

The first test was performed on the specimen with top-and-seat web angle connections. As described above, this specimen is identical, as configuration, with one of the nodes tested by J.M. Reynosa. Repeating this experiment is needed firstly to confirm TSW-10 specimen performances, namely for general comparison of the typologies of joints studied by the author and those available in the literature.

Therefore, reproduction of reference test confirms the credibility of the experimental program, namely the nodes configuration performances proposed for testing by the author, become directly comparable with those in the literature. Figure 3 shows the deformed TSW-10 specimen, included in the experimental program. 


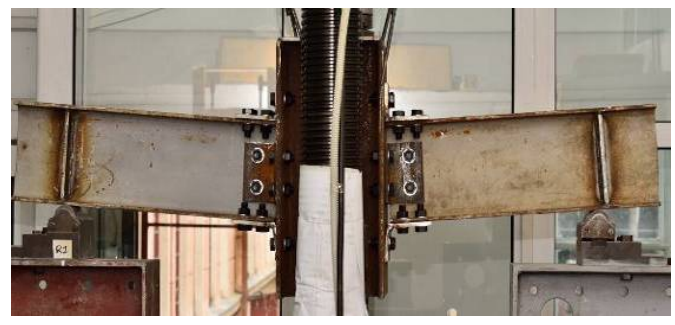

Figure 3. Test on TSW-10 specimen

Figure 4 highlighted the deformation produced in the angle cleats, as well as the relative beamcolumn rotation.

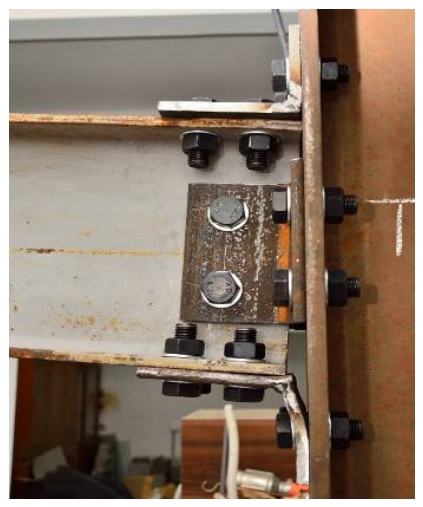

Figure 4. Deformation of angles within the joint

The moment and related beam-column rotation have been assessed using the formulas (1) and (2).

$$
\begin{aligned}
& M=\frac{F}{2} l \\
& \theta_{\text {rel }}=\arctan \frac{\delta}{l}
\end{aligned}
$$

where:

$F=$ total applied load measured by the load cell,

$l=$ distance from the beam support to column face,

$\delta=$ vertical displacement of the beam end at column face and is obtained from the average of the displacements monitored by those two transducers.
The results obtained from laboratory testing of specimen TSW-10 are in good correspondence with the results of the reference experiment (Reynosa, 2014). The characteristic moment-rotation curve obtained for specimen TSW-10 is shown in comparison with the reference result in figure 5 .

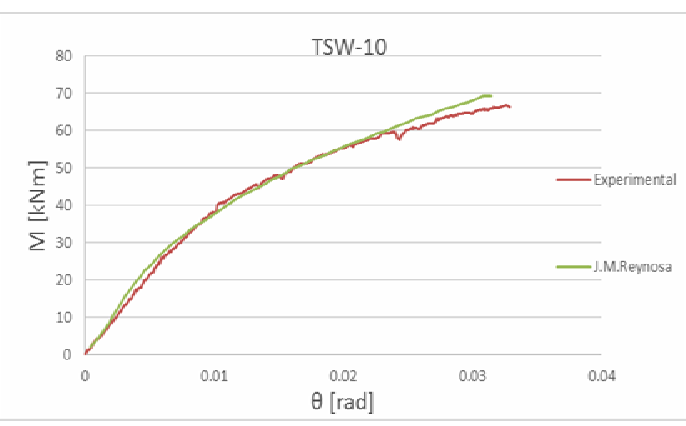

Figure 5. Moment-Rotation behaviour of TSW-10 specimen in compariosn with the reference test result (Reynosa, 2014)

\subsection{TS-10 test}

For this type of joint, referred to as TS-10, is anticipated a poor performance of the joint in comparison with TSW-10, both in terms of stiffness and moment capacity. The deformed shape obtained for TS-10 specimen is shown in figure 6 .

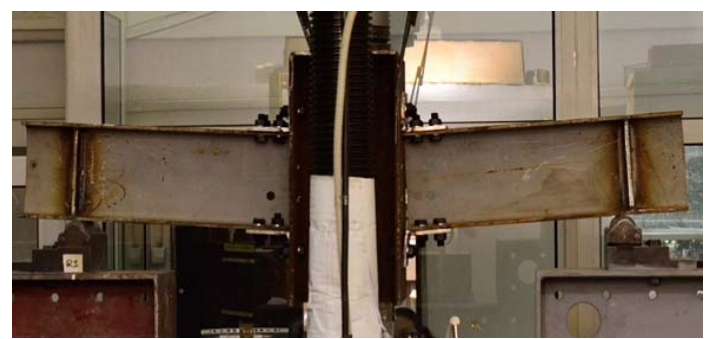

Figure 6. Test on TS-10 specimen

Figure 7 provides in detail the beam-to-column rotation and implicitly the emphasized deformations of the angle from the stretched top-and-seat. 


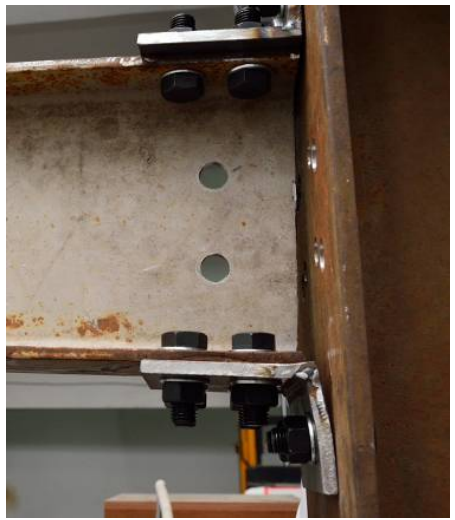

Figure 7. Deformation of seat angle cleat

Compared to specimen TSW-10, which has web angles, the TS-10 is clearly more flexible and can take a lower bending moment. Thus, it can be quantified the contribution of the web angles to the stiffness and moment capacity of joint.

The characteristic moment - rotation curve experimentally obtained has a classical shape with higher stiffness for small values of load, followed by flexibility for high values of loading (figure 8).

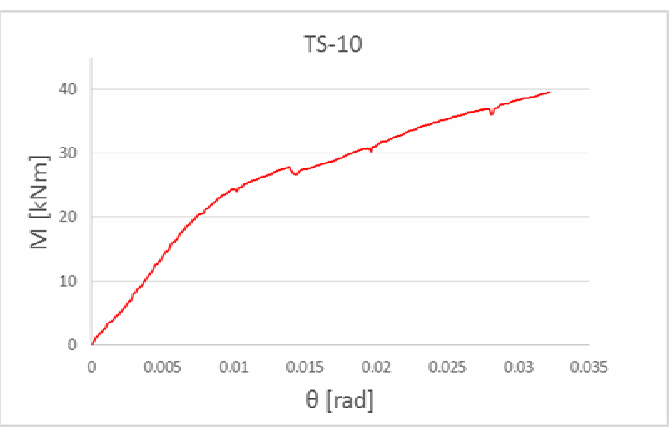

Figure 8. Moment-Rotation behaviour of TS-10 specimen

\subsection{TSS-10 test}

By stiffening of top-and-seat angle cleats it is predicted increase of joints stiffness and strength. The stiffened angle cleat has a substantial contribution to the joint performances, because it prevents and significantly reduces the deformation of this angle, which is the main source of beam-tocolumn rotation. Figure 9 shows the experimental test setup with specimen TSS-10.

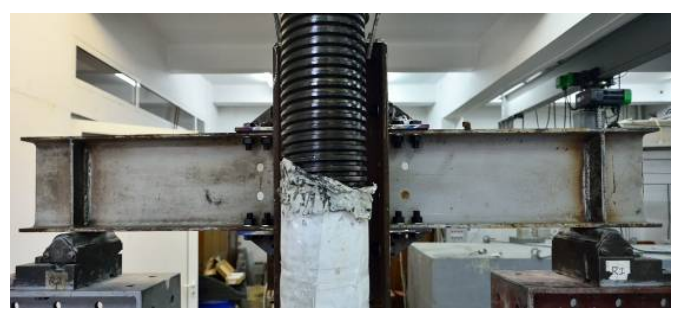

Figure 9. Test setup of TSS-10 specimen

Figure 10 shows the deformation of stiffened angle within the joint.
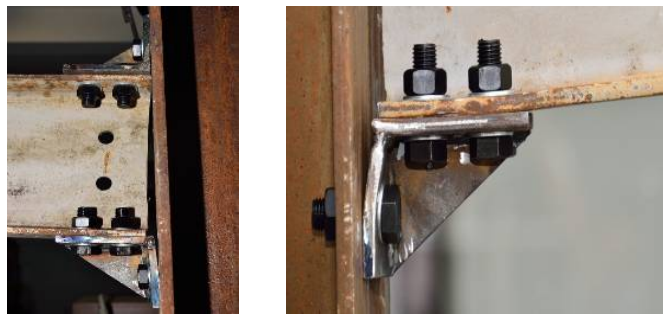

Figure 10. Deformation of stiffened angle

The source of rotation within the joint is the deformation of the angle from the lower chord (tension zone), which in this case is reduced due to the stiffeners. In this case, due to stiffened angle cleats, the angle wing, which is in contact with the column front, shows bending after those two axes corresponding to the unstiffened plates of the angles.

The moment-rotation curve for the tested specimen is shown in figure 11. 


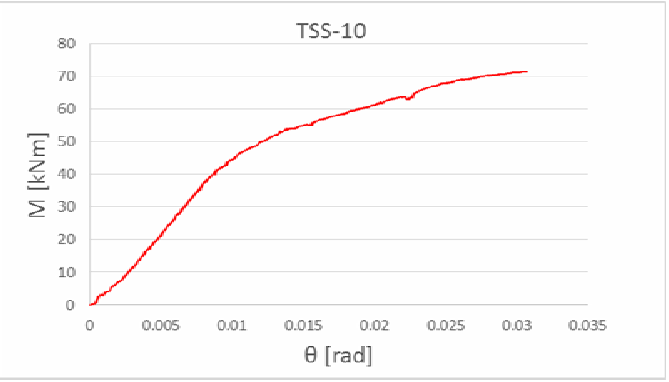

Figure 11. Moment-Rotation behaviour of TSS-10 specimen

\subsection{TSWS-10 test}

The TSWS-10 joint configuration contains all elements used individually in previously tested specimens. The deformed shape of the specimen is shown in figure 12.

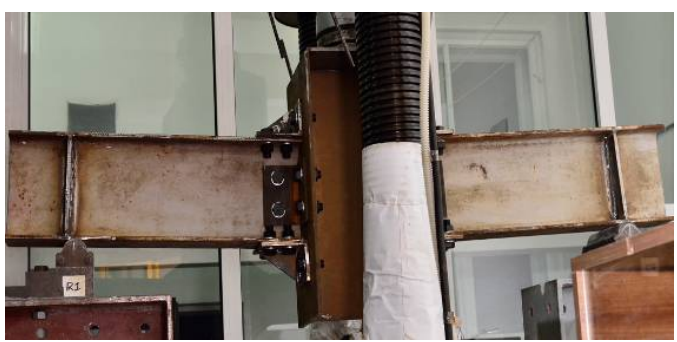

Figure 12. Test on TSWS-10 specimen

Compared to the other specimens the TSWS specimen behaves more rigid. Angle deformation is considerably lower (figure 13). In this test it has been seen a deformation of the lower chord of the connected beam.
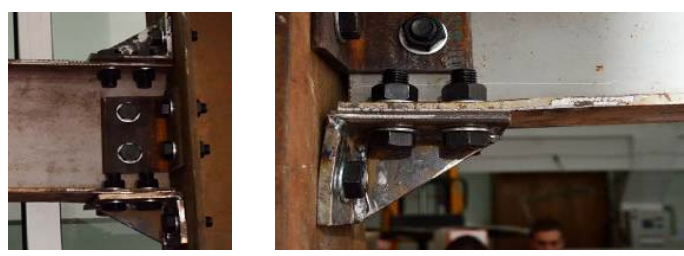

Figure 13. Deformation of angles within the joint
The behavior curve of specimen TSWS-10 is shown in figure 14.

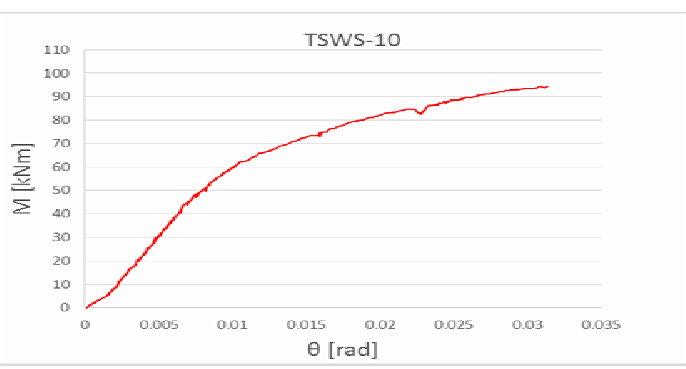

Figure 14. Moment-Rotation behaviour of TSWS10 specimen

\section{DISCUSSION}

Experimental results for those four types of angle joints (TSW-10, TS-10, TSS-10, and TSWS-10) are compared by overlapping the moment-rotation curves.

For all types of connections presented the nonlinear nature of moment-rotation behavior is identified: the connections are more rigid for small values of the moment and become more flexible for higher values (figure 15).

Based on observations it can be concluded that arrangement of web angles is less effective compared to use of stiffened top-and-seat angle cleats.

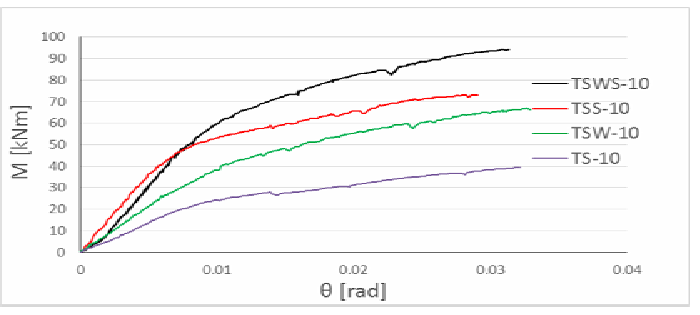

Figure 15. Comparison of connections in terms of moment-rotation behaviour 
The stiffness gain on rotation and moment resistance are highlighted referring to the simple configuration of TS-10.

Table 2 presents the obtained results for the specimens in terms of initial stiffness, moment resistance and differences between the configurations. Based on these results the following remarks can be stated:

- TSW-10 specimen records an increase with $44.72 \%$ of rotation stiffness and an increase of the moment capacity with $63.6 \%$.

- TSS-10 specimen has a considerably higher increase of the initial stiffness, reaching up to $157.30 \%$, the moment capacity has an increase of $86.25 \%$.

- TSWS-10 studied specimen does not record a significant increase of stiffness, reaching only up to $165.89 \%$ and the moment values is almost doubled, reaching up to $138.90 \%$.

\begin{tabular}{|c|c|c|c|c|}
\hline Specimen & $\begin{array}{c}\text { Initial } \\
\text { stiffness } \\
{[\mathrm{kNm} / \mathrm{rad}]}\end{array}$ & $\begin{array}{c}\text { Stiffness } \\
\text { Gain } \\
{[\%]}\end{array}$ & $\begin{array}{c}\text { Moment } \\
\text { resistance } \\
{[\mathrm{kNm}]}\end{array}$ & $\begin{array}{c}\text { Resistance } \\
\text { Gain } \\
{[\%]}\end{array}$ \\
\hline TS-10 & 2712 & reference & 39.3 & reference \\
\hline TSW-10 & 3925 & 44.72 & 64.8 & 63.6 \\
\hline TSS-10 & 6978 & 157.3 & 73.2 & 86.25 \\
\hline TSWS-10 & 7211 & 165.89 & 93.9 & 138.9 \\
\hline
\end{tabular}

Table 2. Joint configuration proposed for testing

The $93 \mathrm{kNm}$ moment value recorded as a maximum value in case of TSWS-10, exceeds the $89 \mathrm{kNm}$ beam moment capacity value (IPE240 made of steel S275), which leads to deformations of the beam. This thing has been also confirmed experimentally. Therefore, it can be said that this joint is totally resistant, and the others are partial resistant.

In figure 15, the behavior of TSWS-10 model shows up to $5 \mathrm{kNm}$, higher flexibility due to the bolt slipping or other anomalies not captured during the testing. After this initial behavior the TSWS-10 specimen takes a constant elastic behavior which is slightly higher than the elastic stiffness of the TSS10 specimen.

\section{CONCLUSIONS}

The experimental program conducted in the concrete laboratory "Cornelia Măgureanu" of the Technical University, Cluj-Napoca included tests on 4 node specimens with double-sided beam-tocolumn connection.

The configurations of joints have been done by eliminating web angles and/or incorporation of some top-and-seat stiffeners. Characteristic moment-rotation curves were obtained.

The experimental results highlighted the main strains and failure modes specific to angle joints.

Initial stiffness and moment resistance of the joints were assessed in order to highlight the gain of the parts, gradually added in their configuration.

The tests have shown that stiffened top-and-seat angle cleats have better performances (in terms of stiffness and strength) compared to web angles.

\section{REFERENCES}

Azizinamini, A., Bradburn, J., (1987). Initial stiffness of semi-rigid steel beam-to-column connections. Journal of Constructional Steel Research 01/1987; 8:pp.71-90.

Pirmoz, A., (2009). Moment-rotation behaviour of bolted top-seat angle connections. Journal of Constructional Steel Research 65 (2009) pp.973-984.

Altman, W. J., (1982). Connections, Moment-Rotation Characteristics of Semi-Rigid Steel Beam-Column. Structural Research Studies, Department of Civil Engineering, University of South Carolina, Columbia.

Csebfalvi, A., (2007). Optimal design of frame structures with semi-rigid joints. Periodica Polytechnica. Civil Engineering, 51/1.

White, D. W., (1996). Characteristic semi-rigid connection relationship for frame analysis and design. Connections in Steel Structures III: Behaviour, Strength 
and Design- De R. Bjorhovde,A. Colson,R. Zandonini. s.l.: Elsevier Science.

Reynosa, J. M., Loureiro, A., (2014). Experimental and numerical study of angle connections assembled with European profiles. Informes de la Construcción Vol. 66, diciembre 2014.

Reynosa, J. M., (2015). Analytical frame approach for the rotational stiffness prediction of beam-to-column angle connections.

Leon, R.T, Jong Wan Hu, Schrauben, C., (2004). Rotational capacity and demand in top-and-seat angle connections subjected to seismic loading. Connections in Steel Structures V - Amsterdam.

Loureiro, A. R., (2011). New proposals on the calculation of the fexural resist- ance in angle connections. Journal of Constructional Steel Research, 67(4): 613-622.

R. Bjorhovde, A. C., (1996). Conections in Steel Structures III - Behaviour, strength \& design. Elsevier Science.

Xiaoguang Lin, H. S. (2004). Experimental study on inelastic behavior and ultimate strenght of steel beam-tocolumn connections with bolts and angles. 13 World Conference on Earthquake Engineering Vancouver, B.C., Canada August 1-6, 2004 Paper No. 1673.

Azizinamini, A., (1982). Monotonic response of semirigid steel beam to column connections. M.S. thesis. Columbia: University of South Carolina; 1982.

Alexa P., Moldovan, C., (2005). Structuri metalice alcătuite din bare cu conexiuni elastice. (Structures with bars with elastic connections) Cluj-Napoca: Ed. Risporint.

Ivanyi, M., (2000). Semi-rigid connections in steel frames. Budapest University of Technology and Economics, Budapest, Hungary: Springer-Verlag Wien $\mathrm{GmbH}$.

Mahmoud, H. N., (2011). Seismic behaviour of semi-rigid steel frames (Phd thesis). University of Illinois at Urbana Champaign.

White, A. V., (2003). Experimental testing and analytical modeling of steel semi-rigid connections. Master's Theses. Paper 2468.
HBM Test and Measurement: CatmanEasy software. http://www.hbm.com/en/2290/catman-data-acquisitionsoftware/

HBM Test and Measurement: WA Inductive Displacement Transducer. http://www.hbm.com/en/3058/inductive-displacementtransducer-plunger-wa-1/

HBM Test and Measurement; Spider 8: http://www.hbm.com/en/2464/spider8/ 